\title{
MODELO MATEMÁTICO DE OTIMIZAÇÃO PARA A SELEÇÃO DE AGENTES INDUTORES DE MATURAÇÃO APLICADOS NA CULTURA DA CANA-DE-AÇÚCAR
}

\author{
CARMO, Carlos Roberto Souza ${ }^{1}$
}

\begin{abstract}
RESUMO: Considerando a relevância do setor sucroenergético para a economia brasileira, bem como a necessidade de se produzir metodologias de apoio à tomada de decisões para um segmento econômico tão relevante, a presente pesquisa teve por objetivo propor um modelo matemático de otimização voltado para o planejamento de gastos a serem realizados na aquisição de agentes indutores de maturação, com vistas ao atendimento da demanda total por sacarose de empreendimentos agrícolas produtores de cana-de-açúcar, e, ainda, a escolha das melhores alternativas em relação à identificação, compra e aplicação desse tipo de agente fisiológico. Utilizando técnicas de programação linear inteira e o método de Programação por Metas Ponderadas, ou ainda, Weighted Goal Programming, em três cenários compostos por dezoito, trinta e sessenta talhões, o modelo proposto nesta investigação científica foi implementado e validado computacionalmente, produzindo um conjunto de informações gerenciais que foi além das variáveis relacionadas à produtividade, demanda de sacarose e aos valores orçamentários. Ou seja, foi possível identificar também quanto comprar de cada tipo de maturador, quanto seria gasto por tipo de maturador, e, ainda, em que talhão cada maturador deveria ser aplicado para que se atingisse a máxima produtividade de sacarose mediante a interação entre o respectivo agente indutor e determinada variedade de cana-de-açúcar.
\end{abstract}

Palavras-chave: Maturadores. Programação por Metas Ponderadas. Métodos quantitativos aplicados.

\section{MATHEMATICAL MODEL OF OPTIMIZATION FOR THE SELECTION OF RIPENERS APPLIED IN SUGARCANE CULTURE}

\begin{abstract}
SUMMARY: Considering the relevance of the sugar-energy sector to the Brazilian economy, as well as the need to produce methodologies to support decision-making for such a relevant economic segment, the present research aimed to propose a mathematical optimization model aimed at planning expenses to be incurred in the acquisition of agents that induce maturation (ripeners), with a view to meeting the total demand for sucrose from agricultural enterprises that produce sugarcane, and also the choice of the best alternatives in relation to the identification, purchase and application of this type of chemical agent. Using techniques of whole linear programming and the Weighted Goal Programming method, in three scenarios composed of eighteen, thirty and sixty plots, the model proposed in this scientific investigation was implemented and computationally validated, producing a set of management information that went beyond variables related to sucrose demand and productivity and budget values. In other words, it was also possible to identify how much to buy of each type of ripener, how much would be spent per type of ripener, and also, in which field each ripener should be applied in order to achieve maximum sucrose productivity through the interaction between the respective chemical inducing agent and certain variety of sugarcane.
\end{abstract}

Keywords: Ripeners. Weighted Goal Programming. Quantitative methods applied.

\section{INTRODUÇÃO}

A cana-de-açúcar é o produto agrícola brasileiro com a terceira maior área cultivada no país (LORIZOLA; CAPITANI, 2018). Com uma área plantada total em torno de nove milhões de hectares, predominantemente na região centro-sul, além da região Nordeste, observa-se um volume de investimentos internacionais crescente neste segmento econômico, além do aumento das operações de fusões e incorporações de empresas do setor sucroenergético do Brasil (LORIZOLA; CAPITANI, 2018).

\footnotetext{
${ }^{1}$ ORCID iD - https://orcid.org/0000-0002-3806-9228 Faculdade de Ciências Contábeis da Universidade Federal de Uberlândia
} 
Diante da intensificação das atividades econômico-produtivas relacionadas à cultura da cana-de-açúcar, é natural que a busca por maiores níveis de produtividade e menores custos se intensifique também, pois, conforme observam Nervis et al. (2017), com o crescimento do setor sucroenergético, a complexidade dos problemas desse segmento têm aumentado consideravelmente, e isso, por sua vez, faz com que as demandas relacionadas à produção de conhecimento voltado para a otimização da produção, colheita e processamento da cana-deaçúcar se intensificassem e diversificassem.

Especialmente em relação aos problemas técnico-operacionais envolvendo o manejo da colheita, pode-se observar que as diversas cultivares de cana-de-açúcar plantadas em um mesmo empreendimento agrícola tendem a atingir os respectivos pontos de maturação e colheita de forma simultânea ou, no mínimo, em intervalos de tempo muito próximos ou até sobrepostos.

A fim de realizar o manejo da colheita da cana-de-açúcar de forma a melhorar o planejamento da safra, os produtores brasileiros têm feito uso de agentes fisiológicos indutores de maturação. Além de facilitar o planejamento da safra e flexibilizar a gestão da colheita, os agentes indutores de maturação também possuem a capacidade melhorar a qualidade da matériaprima demandada pelas indústrias do setor sucroenergético (VIANA et al., 2017).

Contudo, independentemente das facilidades proporcionadas pelo uso dos indutores de maturação, o investimento realizado neste tipo de substância deve proporcionar o respectivo retorno, e nesse sentido, a relação entre investimento realizado e retorno esperado assume grande relevância.

$\mathrm{Na}$ cultura da cana-de-açúcar, o processo de seleção do melhor agente indutor de maturação disponível, ao menor custo de aquisição possível, pode assumir graus muito elevados de complexidade, pois, nem sempre o agente com menor custo é capaz de apresentar os melhores resultados, ou ainda, os resultados decorrentes da aplicação de determinado agente fisiológico em certo cultivar de cana-de-açúcar podem não ser os mesmos quando utilizado em outro tipo de cultivar.

Nesse contexto, a presente pesquisa teve por objetivo propor um modelo matemático de otimização voltado para o suporte à tomada de decisões envolvendo o planejamento de gastos decorrentes da aquisição de agentes indutores de maturação, com vistas ao atendimento da demanda total por sacarose de empreendimentos produtores de cana-de-açúcar ao longo da respectiva safra.

Para atingir o objetivo proposto para esta investigação científica, inicialmente, buscou-se promover o embasamento teórico acerca da temática relacionada ao processo de maturação da cana-de-açúcar e, ainda, foram analisados os resultados de pesquisas com experimentos 
envolvendo o uso dos maturadores e seus efeitos sobre a produtividade de sacarose da cana. A seguir, foi pesquisado e apresentado o modelo matemático de otimização objeto de estudo desta pesquisa, e ainda, foi definido o respectivo método de solução. Na sequência, foi descrito o processo de formação da base de dados que viabilizou a realização dos testes computacionais implementados para validação do modelo proposto. Por fim, foram analisados os resultados identificados a partir dos testes computacionais realizados para validação do modelo de otimização proposto na presente investigação científica.

\section{REFERENCIAL TEÓRICO}

A cultura da cana-de-açúcar passa por quatro estágios fenológicos bem característicos, ou seja, emergência, estabelecimento, desenvolvimento e maturação, conforme resumido na Figura 1 (MARIN et al., 2009).

Figura 1 - Estágios fenológicos da cana-de-açúcar

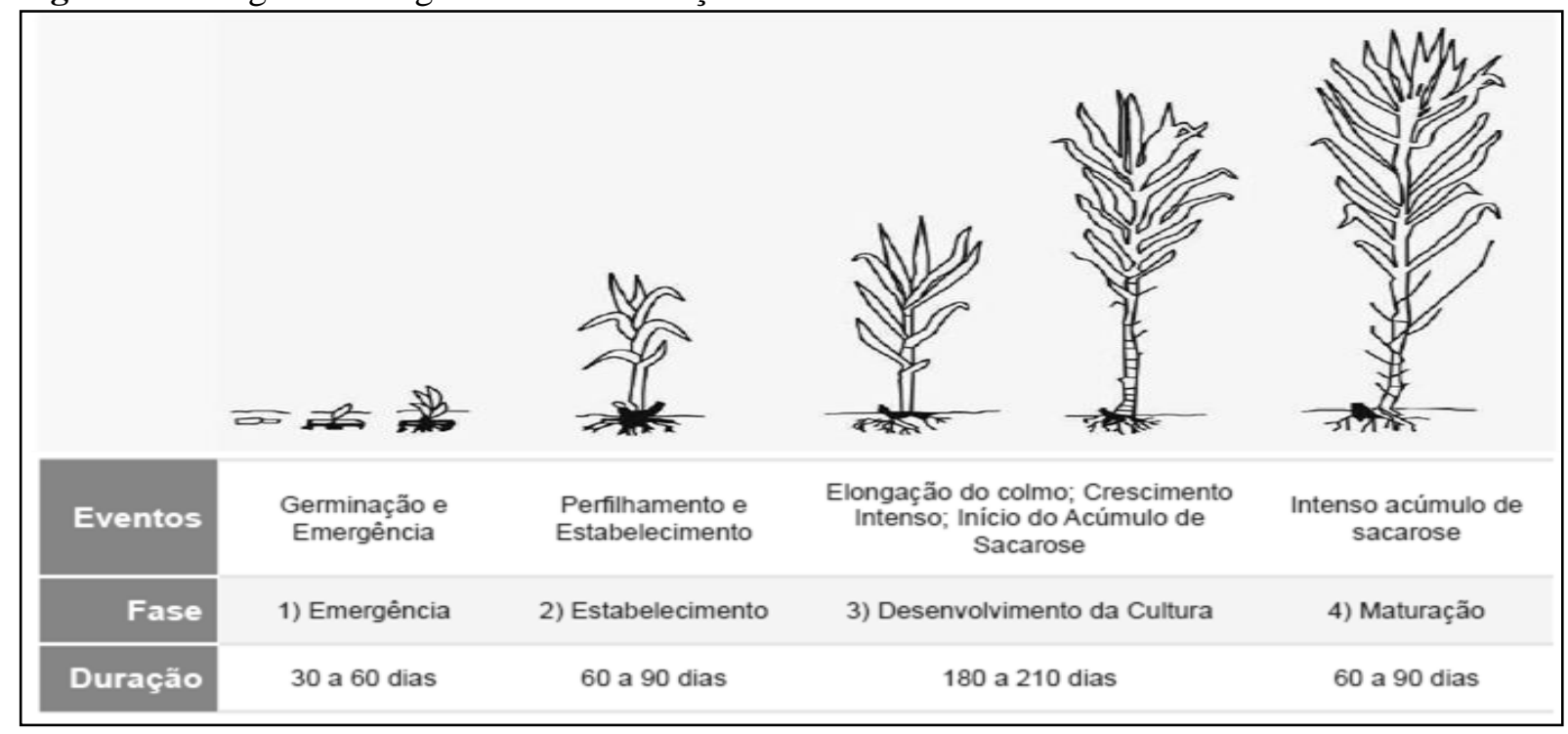

Fonte: Marin et al. (2009, p.115).

Especificamente nos meses finais do ciclo da cultura, a cana-de-açúcar diminui o seu crescimento vegetativo e passa a acumular sacarose de forma mais intensa, dando início à fase da maturação.

O processo de maturação pode ser iniciado naturalmente a partir da ocorrência de algum tipo de estresse ambiental, por exemplo, deficiência hídrica, redução do fotoperíodo ou o frio (MARIN et al., 2009), ou pode ser induzida quimicamente com o auxílio de agentes indutores de maturação.

Do ponto de vista econômico, a maturação natural da cana-de-açúcar não é considerada economicamente viável e, do ponto de vista técnico-fisiológico, a maturação induzida por estresse hídrico só é possível nas áreas de cultivo irrigado, como acontece em algumas regiões 
produtoras do nordeste brasileiro. Dessa forma, os produtores costumam lançar mão do uso de agentes indutores de maturação (maturadores) para viabilizar economicamente o processo de maturação da cana e facilitar o manejo do processo de colheita (LOPES, 2011; ROBERTO et al., 2015).

De acordo com Leite, Crusciol e Silva (2011), os maturadores podem ser definidos como agentes reguladores formados por compostos químicos destinados a alterar a morfologia e fisiologia vegetal, de forma a retardar o seu desenvolvimento vegetativo e induzir a translocação e o armazenamento da sacarose, caracterizando-se como um meio auxiliar do processo de planejamento da colheita da cana, bem como, do seu manejo varietal.

Os resultados de investigações como a de Viana et al. (2015) sinalizam que, devido às alterações geradas no ambiente produtivo, a utilização de maturadores pode provocar desarranjos de natureza morfofisiológicas nas plantas. Por outro lado, algumas pesquisas sobre a ação dos maturadores também indicam que, além de permitir o planejamento da safra a partir da flexibilização em relação ao momento de realização da colheita da cana-de-açúcar, os maturadores podem melhorar a qualidade da matéria-prima demandada pela indústria sucroenergética (DIDIER et al., 2017; INOUE et al., 2015; OLIVEIRA FILHO et al., 2016; CRUSCIOL et al.,2017).

De uma maneira geral, os resultados das pesquisas relacionadas ao uso dos maturadores e seus efeitos sobre a produtividade de sacarose da cana indicam que os diferentes agentes utilizados apresentam ações distintas entre si, ou ainda, diferentes resultados para um mesmo maturador, de acordo com a cultivar em que é aplicado, ou o local de utilização, sua combinação com outras substâncias, entre fatores, conforme mostram a informações contidas no Quadro 2.

Quadro 2 - Resultados de pesquisas relacionadas ao uso de maturadores na cultura da cana-de-açúcar

\begin{tabular}{|l|l|l|}
\hline \multicolumn{1}{|c|}{ Principal objetivo de estudo } & \multicolumn{1}{|c|}{ Fonte } & \multicolumn{1}{|c|}{ Principal resultado } \\
\hline $\begin{array}{l}\text { Avaliar a eficiência do bispiribaque sódico } \\
\text { utilizado como maturador químico na cultura da } \\
\text { cana-de-açúcar, comparativamente à ação do } \\
\text { sulfometuron-metil e do etil-trinexapac. }\end{array}$ & $\begin{array}{l}\text { Intre outros resultados, foi observado que } \\
(2015) \\
\text { todos os tratamentos com maturadores } \\
\text { proporcionaram aumento dos níveis } \\
\text { percentuais de sacarose presente no caldo da } \\
\text { cana (Pol), sem a ocorrência de decréscimos } \\
\text { na produtividade agrícola. }\end{array}$ \\
\hline $\begin{array}{l}\text { Avaliar as respostas fisiológicas da cana-de- } \\
\text { açúcar a partir de tratamentos com indutor de } \\
\text { maturação (ethephon a 480 g ha-1) em duas } \\
\text { variedades de cana-de-açúcar (IACSP95-5000 a a } \\
\begin{array}{l}\text { IACSP94-2094), e, ainda, sua associação ao } \\
\text { déficit hídrico. }\end{array}\end{array}$ & $\begin{array}{l}\text { O efeito do ethephon na cana-de-açúcar foi } \\
\text { genótipo-dependente, sendo capaz de } \\
\text { estimular o acúmulo de sacarose na } \\
\text { variedade responsiva (IACSP95-5000), e, a } \\
\text { associação entre a aplicação do ethephon e } \\
\text { déficit hídrico não aumentou o teor de } \\
\text { sacarose. }\end{array}$ \\
\hline
\end{tabular}


Quadro 2 - Resultados de pesquisas relacionadas ao uso de maturadores na cultura da cana-de-açúcar

(Conclusão)

\begin{tabular}{|c|c|c|}
\hline $\begin{array}{l}\text { Avaliar comparativamente os efeitos de seis } \\
\text { maturadores químicos (glifosato, paraquat, } \\
\text { fluazifop-butil, ethephon, etil-trinexapac, } \\
\text { sulfometuron metil) e o nitrato de potássio } \\
\text { (KNO3) sobre as variáveis relacionadas à } \\
\text { produtividade agrícola (quantidade de colmos por } \\
\text { hectare, diâmetro médio e tonelada produzida por } \\
\text { hectare) e variáveis tecnológico-qualitativas da } \\
\text { cana (Brix, Pol e açúcar recuperável), }\end{array}$ & $\begin{array}{l}\text { Oliveira } \\
\text { Filho et al. } \\
(2016)\end{array}$ & $\begin{array}{l}\mathrm{O}^{\mathrm{KNO}_{3}} \text { contribuiu para melhoria da } \\
\text { qualidade tecnológica da cana, pois, } \\
\text { promoveu o aumento da produtividade } \\
\text { agrícola dos colmos. Em relação às } \\
\text { variáveis tecnológico-qualitativas da cana, o } \\
\text { sulfometuron metil e o } \mathrm{KNO}_{3} \text { promoveram } \\
\text { incrementos nos níveis percentuais de } \\
\text { sacarose presente no caldo da cana (Pol), } \\
\text { entre outros parâmetros. }\end{array}$ \\
\hline $\begin{array}{l}\text { Comparar os resultados do glifosato e do etil- } \\
\text { trinexapac em relação à produtividade agrícola da } \\
\text { cana e ao rendimento tecnológico-qualitativo } \\
\text { (incremento de sacarose), considerando que esses } \\
\text { dois compostos atuam em diferentes processos } \\
\text { bioquímicos. }\end{array}$ & $\begin{array}{l}\text { Orgeron et } \\
\text { al. }(2016)\end{array}$ & $\begin{array}{l}\text { O etil-trinexapac aumentou a concentração } \\
\text { de sacarose em } 8,7 \% \text { e o glifosato em } 13 \% \text {. } \\
\text { Contudo, o etil-trinexapac reduziu o } \\
\text { rendimento agrícola de cana-de-açúcar } \\
\text { (produtividade de cana), e, por sua vez, o } \\
\text { glifosato não reduziu a } \\
\text { produtividade/rendimento agrícola. }\end{array}$ \\
\hline $\begin{array}{l}\text { Avaliar os efeitos do amadurecimento induzido } \\
\text { com fluazifop-butil na produção de cana-de- } \\
\text { açúcar e no seu teor de açúcar. }\end{array}$ & $\begin{array}{l}\text { Muhwiridz } \\
\text { wa et al. } \\
(2016)\end{array}$ & $\begin{array}{l}\text { O fluazifop-butil aumentou o rendimento de } \\
\text { açúcar por hectare de cana-de-açúcar, } \\
\text { embora ele possa provocar reduções na } \\
\text { produtividade agrícola da cana-de-açúcar. }\end{array}$ \\
\hline $\begin{array}{l}\text { Avaliar os parâmetros de qualidade tecnológica } \\
\text { (Brix, Pol, açúcares redutores, açúcares redutores } \\
\text { totais, fibra, pureza, umidade e açúcar teórico } \\
\text { recuperável) e produtivos (toneladas de colmos } \\
\text { por hectare e toneladas de açúcar por hectare) da } \\
\text { cana-de-açúcar submetida à aplicação dos } \\
\text { maturadores químicos glifosato e ethephon, bem } \\
\text { como, de compostos de radicais carboxílicos } \\
\text { orgânicos, no início de safra. }\end{array}$ & $\begin{array}{l}\text { Viana et al. } \\
(2017)\end{array}$ & $\begin{array}{l}\text { A aplicação de glifosato em conjunto com } \\
\text { os compostos de radicais carboxílicos } \\
\text { orgânicos propiciou um maior incremento } \\
\text { nos parâmetros tecnológico-qualitativo da } \\
\text { cana-de-açúcar a partir de } 15 \text { dias após a } \\
\text { aplicação, e, a aplicação do glifosato causou } \\
\text { incrementos após } 30 \text { da aplicação. }\end{array}$ \\
\hline $\begin{array}{l}\text { Avaliar a influência dos reguladores vegetais da } \\
\text { classe dos inibidores de crescimento } \\
\text { sulfometuron metil, glifosato e compostos de } \\
\text { radicais carboxílicos orgânicos misturados ao } \\
\text { glifosato, no desenvolvimento da cana-de-açúcar, } \\
\text { no acúmulo de sacarose (Pol), na produtividade } \\
\text { de colmos, na atividade invertase e n rebrotação } \\
\text { da soqueira, no meio da safra. }\end{array}$ & $\begin{array}{l}\text { Crusciol et } \\
\text { al. (2017) }\end{array}$ & $\begin{array}{l}\text { O uso dos reguladores vegetais influenciou } \\
\text { positivamente a qualidade tecnológica da } \\
\text { cana, com especial atenção ao aumento do } \\
\text { teor de polpa. Adicionalmente, foi } \\
\text { constatado que, sob condições climáticas } \\
\text { desfavoráveis ao amadurecimento, o } \\
\text { sulfometuron metil e glifosato foram mais } \\
\text { eficientes em relação ao aumento do teor de } \\
\text { sacarose, comparativamente ao tratamento } \\
\text { com a mistura de compostos carboxílicos } \\
\text { orgânicos e glifosato }\end{array}$ \\
\hline $\begin{array}{l}\text { Determinar a melhor resposta de certas } \\
\text { variedades de cana-de-açúcar (NCo376 e } \\
\text { SP711406) cultivadas na região norte da Costa do } \\
\text { Marfim, em relação ao efeito de maturação do } \\
\text { glifosato e ao atraso na colheita após sua } \\
\text { aplicação. }\end{array}$ & $\begin{array}{l}\text { Didier } \text { et al } \\
(2017)\end{array}$ & $\begin{array}{l}\text { O glifosato melhorou o teor de sacarose e o } \\
\text { açúcar recuperável das variedades tratadas. } \\
\text { Foram constatados incrementos de sacarose } \\
\text { na ordem de } 1,6 \% \text { e de açúcar recuperável } \\
\text { em torno de } 1,5 \% \text { de açúcar. }\end{array}$ \\
\hline
\end{tabular}

Fonte: elaborado pelo autor, a partir dos dados pesquisa.

Conforme pode ser visto no Quadro 2, uma das principais medidas utilizadas para avaliar os efeitos dos maturadores sobre a produtividade da cana-de-açúcar é o nível percentual de sacarose presente do caldo da cana (Pol), além de outras medidas como Brix, pureza, percentual de fibra e dos açúcares redutores, entre outras.

Os níveis de Pol assumem grande relevância no processo de planejamento do plantio até a industrialização, passando pelos processos de cultivo e colheita. A Pol tende a variar de acordo 
com o estágio fenológico em que a cana se encontra, mas, na maturação, ela passa a assumir maior relevância, visto que, ela está diretamente relacionada à qualidade da cana-de-açúcar destinada ao processo de industrialização.

Os níveis de Pol caracterizam-se como um importante indicador utilizado para definir o intervalo em que a cana-de-açúcar apresenta teores satisfatórios de sacarose para a sua utilização pela indústria sucroenergética, sendo que, a existência de teores satisfatórios de sacarose não indica o teor máximo que determinada variedade pode atingir. Ou seja, teores satisfatórios de sacarose representam o teor mínimo recomendado para o processo de industrialização da cana-deaçúcar, dentro do chamado período útil de industrialização (PUI) (LOPES, 2011), conforme mostra a Figura 2

Figura 2 - Curvas de produção de sacarose e a Pol da cana-de-açúcar

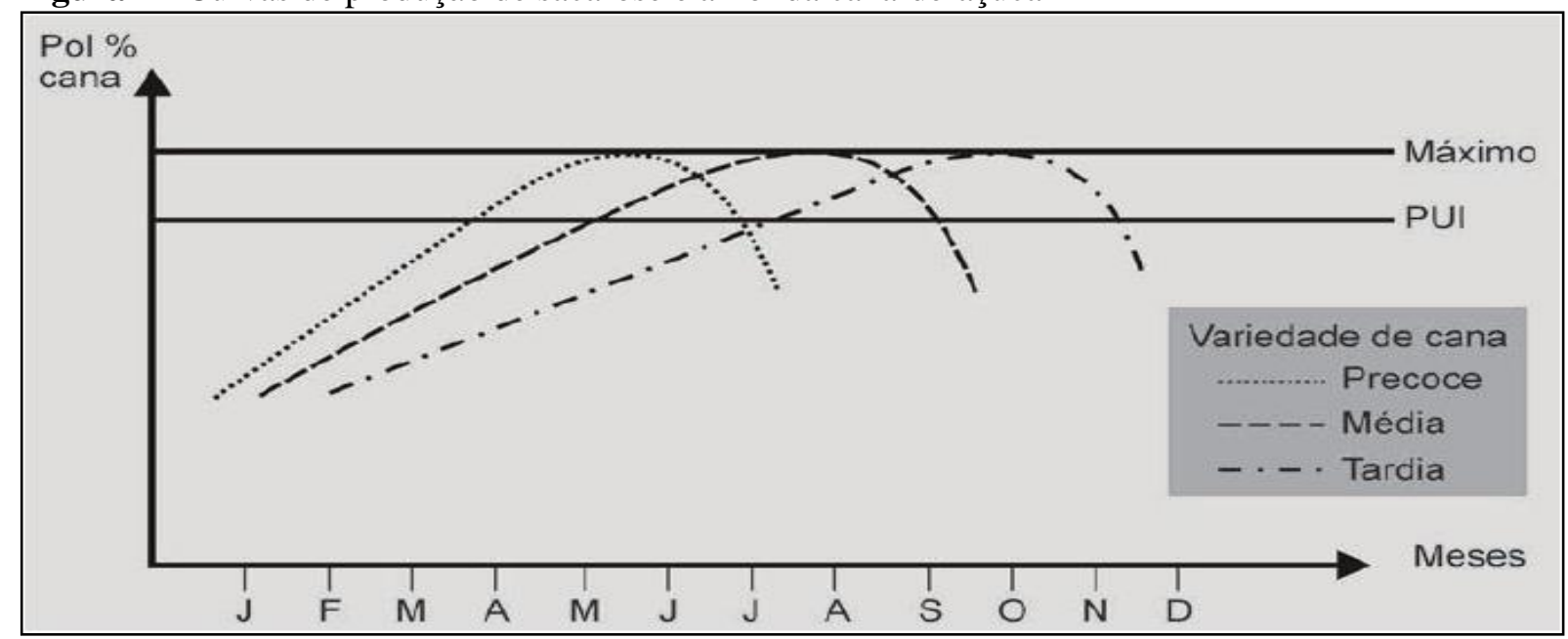

Fonte: Lopes (2011, p.41).

Ao relacionar a época de maturação com os níveis de Pol considerados satisfatórios para o processo de industrialização, na região Centro-sul do Brasil, as variedades de cana-de-açúcar podem ser classificadas como precoces, médias ou tardias, isto é: quando a maturação ocorre de maio a junho, a variedade é considerada precoce; quando a maturação ocorre entre julho e setembro, a variedade é denominada média; e, quando a maturação ocorre a partir do mês de outubro até o final da safra, a variedade é considerada tardia (LOPES, 2011).

Diante do exposto, pode-se afirmar que o planejamento envolvendo a cultura da cana-deaçúcar é uma tarefa complexa e requer o conhecimento de um número elevado de variáveis que precisam ser combinadas para que se possa produzir informações suficientes para fornecer o devido suporte a tomada de decisões relacionadas ao cultivo dessa cultura.

Nesse conjunto de variáveis e informações, destacam-se aquelas relacionadas à utilização dos maturadores, que se apresentam como uma alternativa útil ao processo de melhoria da 
matéria-prima utilizada pelo setor sucroenergético e ao planejamento e manejo do processo de colheita da cana-de-açúcar.

Contudo, a identificação e a compreensão dos relacionamentos das variáveis relacionadas às decisões envolvendo a seleção de maturadores não é tarefa fácil. Por isso, espera-se que o modelo matemático proposto nesta pesquisa possa ser de grande utilidade à produção de informações gerenciais demandadas pela tomada de decisões pertinentes aos gastos envolvendo esse tipo de substância largamente utilizada no manejo da cultura da cana-de-açúcar.

\section{METODOLOGIA DE PESQUISA}

Uma vez que o modelo proposto nesta pesquisa buscou minimizar possíveis desvios negativos (para baixo) entre a quantidade de sacarose produzida e a quantidade necessária para atender a demanda total de empreendimentos agrícolas produtores de cana-de-açúcar, e, ainda, evitar possíveis desvios positivos (para cima) que pudessem fazer com que os valores gastos com maturadores fossem maior que o respectivo orçamento de compras, optou-se pelo processo de modelagem baseado no método de Programação por Metas Ponderada (PMP), ou Weighted Goal Programming (WGP), conforme proposto por Jones e Tamiz (2010), cuja a forma algébrica é descrita pelas Equações 1 a 3.

$$
\text { Minimize } \quad z=\sum_{i=1}^{k} u_{i} n_{i}+v_{i} p_{i}
$$

Sujeito a:

$$
\begin{aligned}
& f_{i}(x)-p_{i}+n_{i}=g_{i}, \quad i=1, \ldots, Q \\
& x \in F, \quad p_{i} \geq 0 \text { e } n_{i} \geq 0, \quad i=1, \ldots, Q
\end{aligned}
$$

Nas Equações 1 a 3: $x$ é um vetor de variáveis; $f_{i}(x)$ é uma função de $x ; g_{i}$ é valor meta; $n_{i}$ e $p_{i}$ são, respectivamente, os valores dos desvios abaixo e acima do valor meta; $u_{i}$ e $v_{i}$ são os pesos associados aos desvios indesejáveis $n_{i}$ e $p_{i}$, com $i=1, \ldots, Q$, respectivamente, na função $z$, os quais assumem valores de acordo com a importância de cada meta, sendo que, usa-se

$\sum_{i=1}^{k}\left(u_{i}+v_{i}\right)=1$, e, ainda, usa-se $f_{i}$ normalizada $\left(\frac{f_{i}(x)}{g_{i}}, g_{i} \neq 0\right), i=1, \ldots, Q$, caso as metas apresentem unidades de medidas distintas.

A justificativa para utilização do método de PMP proposto por Jones e Tamiz (2010) reside no fato de que essa metodologia utiliza o conceito de factibilidade de execução. Isto é, ao buscar direcionar desvios indesejados para mínimo possível, viabiliza-se o atendimento de um ou 
mais objetivos, permitindo ao tomador de decisão aproximar suas metas de uma solução factível (COLAPINTO; JAYARAMAN; MARSIGLIO, 2017).

A implementação computacional e a validação do modelo proposto foram realizadas utilizando técnicas baseadas em problemas de programação linear inteira (PLI), em três cenários formados por instâncias geradas aleatoriamente de forma a reproduzir situações reais de empreendimentos agrícolas produtores de cana-de-açúcar da região centro-sul do Brasil, cuja resolução ocorreu com o uso do pacote analítico SOLVER, disponível em planilhas eletrônicas de cálculo e, ainda, um computador com processador Intel Core ${ }^{\circledR}$ i5 2,30 GHz com 8,00 GB de memória RAM instalada.

Assim, a seção 3.1 descreve o modelo matemático proposto nesta pesquisa e seu funcionamento, e a seção 3.2 detalha os procedimentos desenvolvidos para viabilizar a composição da base de dados utilizada para validação do modelo em questão mediante a realização de testes computacionais.

\subsection{Modelo de Otimização para Seleção de Agentes Indutores de Maturação}

Em relação ao planejamento anual da safra de cana-de-açúcar, o problema de otimização a ser resolvido pelo modelo proposto nesta investigação consiste na identificação e escolha do

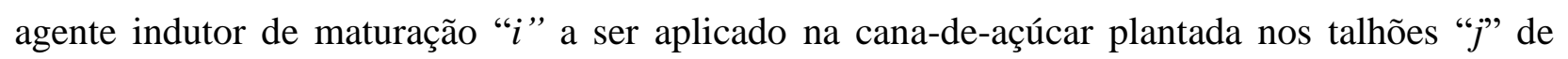
empreendimentos agrícolas do setor sucroenergético, de forma que sejam minimizados possíveis desvios negativos " $n_{1}$ " (para baixo) em relação à quantidade de sacarose produzida, comparativamente à respectiva quantidade demandada “ $D$ ”, e, ainda, minimizar possíveis desvios positivos " $p_{2}$ " (para cima) referentes aos montantes gastos na aquisição de maturadores a serem utilizados na cultura da cana-de-açúcar, comparativamente ao respectivo orçamento total de compras " $C$ ".

O modelo matemático de otimização em questão tem a sua função objetivo descrita pela Equação 4, que está sujeita às restrições descritas pelas Equações 5 até 8, conforme as variáveis, índices e parâmetros informados no Quadro 3.

Minimize $\left(\frac{n_{1}}{D}\right) u+\left(\frac{p_{2}}{C}\right) v$

Sujeito a:

$$
\sum_{i=1}^{w} X_{i j} H_{j} \text { TCH }_{j} \text { Polmá }_{i}+n_{1}-p_{1}=D, \quad j=1, \ldots, k
$$




$$
\sum_{i=1}^{n w} X_{i j} H_{j} c c_{i}+n_{2}-p_{2}=C, \quad j=1, \ldots, k
$$

$$
\sum_{i=1}^{w} X_{i j}=1, j=1, \ldots, k
$$

$$
X_{i j}=\left\{\begin{array}{l}
1, \text { se aplicar o maturador } i \text { no talhão } j \\
0, \text { em caso contrário }
\end{array}\right.
$$

$$
X_{i j}=0 \text { ou } 1 ; \quad i=1, \ldots, w ; \quad j=1, \ldots, k ; \quad n_{j} \geq 0 ; \quad p_{j} \geq 0
$$

\begin{tabular}{|c|c|c|}
\hline Legenda & Categoria & Descrição \\
\hline$n_{1}$ & desvio & $\begin{array}{l}\text { Desvio negativo (abaixo), medido em toneladas (t), em relação ao total de } \\
\text { sacarose produzida pela cana plantada nos talhões } j \text { e a respectiva } \\
\text { quantidade demandada }(D) \text { para a safra. }\end{array}$ \\
\hline$p_{1}$ & desvio & $\begin{array}{l}\text { Desvio positivo (acima), medido em toneladas (t), em relação ao total de } \\
\text { sacarose produzida pela cana plantada nos talhões } j \text { e a respectiva } \\
\text { quantidade demandada }(D) \text { para a safra. }\end{array}$ \\
\hline$n_{2}$ & desvio & $\begin{array}{l}\text { Desvio negativo (abaixo), medido em moeda }(\mathrm{R} \$) \text {, em relação ao total de } \\
\text { gasto para a aquisição dos maturadores } i \text { a serem aplicados na cana plantada } \\
\text { nos talhões } j \text {, comparativamente ao respectivo orçamento de compras }(C) \\
\text { para toda a safra. }\end{array}$ \\
\hline$p_{2}$ & desvio & $\begin{array}{l}\text { Desvio positivo (acima), medido em moeda }(\mathrm{R} \$) \text {, em relação ao total de } \\
\text { gasto para a aquisição dos maturadores } i \text { a serem aplicados na cana plantada } \\
\text { nos talhões } j \text {, comparativamente ao respectivo orçamento de compras }(C) \\
\text { para toda a safra. }\end{array}$ \\
\hline$\overline{X_{i j}}$ & $\begin{array}{l}\text { Variável de } \\
\text { decisão }\end{array}$ & $\begin{array}{l}\text { Assumirá valor } 1 \text { (um,) se o maturador } i \text { for aplicado na cana-de-açúcar } \\
\text { plantada no talhão } j \text {, ou assumirá valor } 0 \text { (zero) em caso contrário. }\end{array}$ \\
\hline$j=1, \ldots, k$ & índice & Índices que representam os talhões em que se encontra plantada a cana-de-açúcar. \\
\hline$i=1, \ldots, w$ & índice & $\begin{array}{l}\text { Índices que representam os maturadores a serem aplicados na cana-de-açúcar } \\
\text { plantada nos talhões } j .\end{array}$ \\
\hline$u_{j}, v_{j}$ & parâmetro & $\begin{array}{l}\text { Pesos associados aos desvios negativos }\left(u_{j}\right) \text { e positivos }\left(v_{j}\right) \text { a serem } \\
\text { minimizados pelo modelo, sendo que, a atribuição de tais pesos leva em } \\
\text { conta as preferências estabelecidas pelo tomador de decisões de acordo com } \\
\text { suas prioridades em relação à cada desvio e a respectiva meta. }\end{array}$ \\
\hline$D$ & parâmetro & $\begin{array}{l}\text { Quantidade total de sacarose demandada, medida em toneladas }(\mathrm{t}) \text {, para toda } \\
\text { safra em planejamento. }\end{array}$ \\
\hline$C$ & parâmetro & $\begin{array}{l}\text { Orçamento total, medido em moeda (R\$), destinado à aquisição de } \\
\text { maturadores para toda safra em planejamento. }\end{array}$ \\
\hline$H_{j}$ & parâmetro & $\begin{array}{l}\text { Indica a dimensão, em hectares (ha), de cada talhão } j \text { em que a cana-de- } \\
\text { açúcar se encontra plantada. }\end{array}$ \\
\hline$T C H_{j}$ & parâmetro & $\begin{array}{l}\text { Indica a produtividade de cana, em toneladas por hectare }\left(\mathrm{t} \mathrm{ha}{ }^{-1}\right) \text {, das } \\
\text { variedades plantadas em cada talhão } j \text {. }\end{array}$ \\
\hline Polmáx $x_{i}$ & parâmetro & $\begin{array}{l}\text { Indica o nível percentual máximo de Pol que cada variedade de cana-de- } \\
\text { açúcar, plantada nos respectivos talhões } j \text {, pode atingir a partir da ação de } \\
\text { um maturador } i \text {. }\end{array}$ \\
\hline$c c_{i}$ & parâmetro & $\begin{array}{l}\text { Preço de compra unitário (custo), medido em moeda (R\$), de cada } \\
\text { maturador } i \text { a ser adquirido para aplicação na cana plantada nos talhões } j \text {. }\end{array}$ \\
\hline
\end{tabular}

Quadro 3 - Descrição dos variáveis, índices e parâmetros do modelo proposto

Fonte: elaborado pelo autor, a partir dos dados pesquisa. 
Na função objetivo descrita pela Equação 4, as variáveis de desvio $n_{1}$ e $p_{2}$ são desvios a serem minimizados, sendo que, $n_{1}$ é o desvio negativo (para baixo) na quantidade de sacarose produzida, comparativamente à respectiva quantidade demanda $(D)$ para toda a safra em planejamento, e $p_{2}$ é o desvio positivo (para cima) no total dos valores gastos para a aquisição de maturadores a serem utilizados na cultura da cana-de-açúcar em relação ao respectivo orçamento total de compras $(C)$. Por se tratar de variáveis mensuradas em unidades de medidas distintas (toneladas de sacarose e valores em moeda), a função objetivo descrita pela Equação 4 foi normalizada $\left(n_{1} / D\right.$ e $\left.p_{2} / C\right)$ de tal forma que os desvios minimizados assumissem valores relativos em uma mesma base, ou seja, valores decimais medidos em relação às respectivas metas. As variáveis $u$ e $v$ são pesos a serem atribuídos a cada desvio minimizado, de acordo com as preferências e/ou prioridades estabelecidas pelo tomador de decisões.

A restrição (5) garante que toda a sacarose produzida $\left(H_{j} T C H_{j}\right.$ Polmáx $\left.x_{i}\right)$ pela cana plantada nos talhões $j$ de um empreendimento produtor atenda à demanda total $(D)$ da safra em planejamento. A produção (rendimento) da sacarose leva em consideração a área de cada talhão $\left(H_{j}\right)$, em hectares, a produção esperada da cana plantada nos respectivos talhões, em toneladas por hectare $\left(T C H_{j}\right)$, e ainda, o percentual máximo de Pol que a cana plantada pode atingir mediante a ação de determinado maturador (Polmáx ${ }_{i}$ ).

A restrição (6) garante que o total dos gastos realizados $\left(H_{j} c c_{i}\right)$ com os maturadores a serem aplicados na cana plantada nos $j$ talhões seja igual ao valor total orçado para sua aquisição $(C)$. O total dos gastos realizados com a aquisição de maturadores leva em conta a área plantada de cada talhão $\left(H_{j}\right)$, em hectares, e ainda, o respectivo custo por hectare do maturador a ser aplicado $\left(c c_{i}\right)$.

A restrição (7) garante que a cana-de-açúcar plantada em todo talhão $j$ receba a aplicação de um único agente indutor de maturação $i$.

As restrições (8-9) determinam os valores a serem atribuídos às variáveis do modelo do modelo (decisão e desvios).

\subsection{Composição da Base de Dados para Realização dos Testes Computacionais}

Na composição da base de dados dos testes computacionais realizados para validação do modelo de otimização proposto, assumiu-se a possibilidade de cada talhão $j$ conter qualquer uma das 18 variedades de cultivares de cana-de-açúcar adaptáveis à região centro-sul do Brasil descritas na Tabela 1, bem como, os respectivos parâmetros de produtividade (TCH e Pol). 
Tabela 1 - Características produtivas de 18 diferentes variedades de cana-de-açúcar adaptáveis à região centro-sul do Brasil

\begin{tabular}{|c|c|c|c|}
\hline \multicolumn{2}{|c|}{ Variedade } & \multicolumn{2}{|c|}{ Produtividade } \\
\hline Número & Identificação & $\begin{array}{c}\text { TCH } \\
\left(\mathrm{t} \mathrm{ha}^{-1}\right)\end{array}$ & $\begin{array}{l}\text { Pol } \\
(\%) \\
\end{array}$ \\
\hline 1 & CTC15 & 132,80 & 14,50 \\
\hline 2 & СТС9 & 100,00 & 15,84 \\
\hline 3 & RB925211 & 89,29 & 14,67 \\
\hline 4 & СТC6 & 136,00 & 14,98 \\
\hline 5 & RB855156 & 117,80 & 14,50 \\
\hline 6 & СТC2 & 129,10 & 14,31 \\
\hline 7 & RB867515 & 148,20 & 14,82 \\
\hline 8 & SP80-1842 & 112,80 & 14,90 \\
\hline 9 & SP83-2847 & 126,70 & 13,20 \\
\hline 10 & SP80-3280 & 121,70 & 14,80 \\
\hline 11 & RB928062 & 113,00 & 15,75 \\
\hline 12 & RB966928 & 123,10 & 13,32 \\
\hline 13 & СТC20 & 165,00 & 13,50 \\
\hline 14 & СТC17 & 112,30 & 14,98 \\
\hline 15 & SP81-3250 & 140,60 & 15,02 \\
\hline 16 & CTC4 & 130,90 & 13,54 \\
\hline 17 & RB92579 & 142,40 & 15,70 \\
\hline 18 & RB855453 & 133,35 & 13,90 \\
\hline
\end{tabular}

Fonte: elaborado pelo autor, a partir de Ramos et al. (2016).

Foram propostos três cenários formados por três instâncias distintas, sendo que, a instância $I-18$ foi composta por 18 talhões, a instância $I-30$ foi composta por 30 talhões e a instância $I-60$ foi composta por 60 talhões. Na instância $I-18$, foi definido que cada talhão $j$ seria ocupado por uma das 18 variedades descritas na Tabela 1. Nas instâncias $I-30$ e I-60, a definição acerca da ocupação de cada talhão $j$ por uma determinada variedade de cana-de-açúcar se deu mediante o sorteio de números aleatórios entre 1 e 18, cuja variedade atribuída a cada talhão aconteceu com base nas informações descritas na Tabela 1.

As dimensões $H_{j}$ de cada talhão $j$, em hectares (ha), foram definidas mediante o sorteio de números aleatórios entre 18 e 48 para todas as instâncias. A área mínima de 18 ha foi estimada a partir de dados referentes ao ano de 2017 para o estado de São Paulo, disponíveis no Censo Agropecuário do Instituto Brasileiro de Geografia e Estatística (IBGE) (SIDRA, 2019), sendo: 4.861.491 ha / 14.910 unidades produtoras $=326$ ha unidade produtiva ${ }^{-1}$, e ainda, 326 ha $/ 18$ variedades $=\overline{H_{\jmath}}=18,11$ ha talhão ${ }^{-1}$. A área máxima de 48 ha foi estabelecida levando-se em conta a recomendação do Centro de Tecnologia Canavieira (CTC) de que cada variedade plantada em uma unidade produtiva deve ocupar, no máximo, $15 \%$ da área total plantada (RAIZER; BRAGA JÚNIOR; SELEGATO, 2013), ou seja: 326 ha x unidade produtiva ${ }^{-1}$ x 0,15 talhão $^{-1}=48,91$ ha talhão ${ }^{-1}$.

A demanda total de sacarose $(D)$ para a safra em planejamento foi estimada com base na capacidade produtiva de cada talhão $j$ dentro das respectivas instâncias $\left(D=\sum_{j=1}^{k} H_{j} T C H_{j} P o l_{j}\right)$ e, ainda, considerando as informações de produtividade descritas na Tabela 1. 
O valor do orçamento total $(C)$ destinado à aquisição de maturadores para a safra em planejamento foi estimado com base na área de cada talhão e no custo unitário médio da dose de maturador a ser aplicada por hectare $\left(C=H_{j} \overline{C c_{l}}\right)$.

Uma vez que os produtores brasileiros utilizam preferencialmente agentes indutores de maturação como o Ethephon e o Etil-trinexapac, além do Glifosato e o Sulfometuron-metil (VIANA et al., 2017), para a realização dos testes computacionais foi simulada a seleção de três tipos de maturadores, sendo dois deles o Ethephon e o Etil-trinexapac, com as respectivas dosagens de aplicação recomendadas pelas bulas dos respectivos fabricantes $\left(0,66 \mathrm{~L} \mathrm{ha}^{-1}\right.$ e $1,00 \mathrm{~L}$ $\mathrm{ha}^{-1}$ ), bem como, os respectivos preços de mercado ( $\mathrm{R} \$ 180,00 \mathrm{~L}$ e $\mathrm{R} \$ 110,00 \mathrm{~L}$ ), e, ainda, uma terceira opção, doravante denominada de "Intermediário", formada a partir da média desses de preços daqueles dois maturadores $\left(\mathrm{R} \$ 114,40 \mathrm{ha}^{-1}\right)$.

Para a estimativa do nível percentual máximo de sacarose (Polmáx $x_{i}$ ) que cada uma daquelas 18 variedade de cana-de-açúcar poderia atingir a partir da ação de um maturador $i$, foi realizado o levantamento dos resultados de estudos anteriores (CAPUTO et al., 2007; INOUE et al., 2015; OLIVEIRA FILHO et al., 2016; VIANA et al., 2008; VIANA et al., 2017), em que, foram identificados os níveis percentuais mínimos e máximos de Pol para cada quantidade de dias após a aplicação dos maturador (DAA), conforme descrito na Tabela 2. Sendo que, a justificativa para a pesquisa dos resultados dos estudos de Caputo et al (2007), Inoue et al (2015), Oliveira Filho et al (2016), Viana et al (2008) e Viana et al (2017), reside no fato de que todas essas investigações científicas realizaram experimentos com os dois maturadores escolhidos para realização dos teste computacionais desta pesquisa, ou seja, o Ethephon e o Etil-trinexapac.

Tabela 2- Dados para simulação das funções de produtividade de Pol a partir da ação dos maturadores

\begin{tabular}{|c|c|c|c|c|c|}
\hline \multirow[t]{3}{*}{ Maturador } & \multirow{3}{*}{$\begin{array}{l}\text { Quantidade de dias após a } \\
\text { aplicação do maturador } \\
\text { (DAA) }\end{array}$} & \multicolumn{2}{|c|}{ Frequência } & \multirow{2}{*}{\multicolumn{2}{|c|}{$\begin{array}{l}\text { Níveis de Pol } \\
(\%)\end{array}$}} \\
\hline & & \multirow{2}{*}{$\begin{array}{l}\text { Absoluta }^{(\mathrm{g})} \\
\quad(n)\end{array}$} & \multirow{2}{*}{$\begin{array}{l}\text { Relativa }^{(\mathrm{h})} \\
(\%)\end{array}$} & & \\
\hline & & & & Mínimo & Máximo \\
\hline \multirow[t]{6}{*}{ Ethephon } & $0^{(\mathrm{a})}$ & 8 & $21 \%$ & 6,26 & 11,05 \\
\hline & $15^{(\mathrm{b})}$ & 3 & $8 \%$ & 11,64 & 13,44 \\
\hline & $30^{(c)}$ & 10 & $26 \%$ & 10,01 & 14,38 \\
\hline & $45^{(\mathrm{d})}$ & 8 & $21 \%$ & 11,87 & 15,41 \\
\hline & $60^{(\mathrm{e})}$ & 2 & $5 \%$ & 14,91 & 16,62 \\
\hline & $75^{(\mathrm{f})}$ & 8 & $21 \%$ & 13,15 & 16,99 \\
\hline \multirow[t]{6}{*}{ Etil-trinexapac } & $0^{(\mathrm{a})}$ & 1 & $14 \%$ & 10,3 & 10,3 \\
\hline & $15^{(\mathrm{b})}$ & 2 & $29 \%$ & 11,8 & 13,48 \\
\hline & $30^{(\mathrm{c})}$ & 1 & $14 \%$ & 14,54 & 14,54 \\
\hline & $45^{(\mathrm{d})}$ & 0 & $0 \%$ & & \\
\hline & $60^{(\mathrm{e})}$ & 2 & $29 \%$ & 13,97 & 15,69 \\
\hline & $75^{(\mathrm{f})}$ & 1 & $14 \%$ & 15,34 & 15,34 \\
\hline
\end{tabular}


Tabela 2- Dados para simulação das funções de produtividade de Pol a partir da ação dos maturadores

\begin{tabular}{|c|c|c|c|c|c|}
\hline \multirow{3}{*}{ Maturador } & \multirow{3}{*}{$\begin{array}{l}\text { Quantidade de dias após a } \\
\text { aplicação do maturador } \\
\text { (DAA) }\end{array}$} & \multicolumn{2}{|c|}{ Frequência } & \multirow{2}{*}{\multicolumn{2}{|c|}{$\begin{array}{c}\text { Níveis de Pol } \\
(\%)\end{array}$}} \\
\hline & & \multirow{2}{*}{$\begin{array}{l}\text { Absoluta }^{(\mathrm{g})} \\
(n)\end{array}$} & \multirow{2}{*}{$\begin{array}{c}\text { Relativa }^{(\mathrm{h})} \\
(\%)\end{array}$} & & \\
\hline & & & & Mínimo & Máximo \\
\hline \multirow[t]{6}{*}{ Intermediário } & $0^{(a)}$ & 9 & $20 \%$ & 6,26 & 11,05 \\
\hline & $15^{(\mathrm{b})}$ & 5 & $11 \%$ & 11,64 & 13,48 \\
\hline & $30^{(\mathrm{c})}$ & 11 & $24 \%$ & 10,01 & 14,54 \\
\hline & $45^{(\mathrm{d})}$ & 8 & $17 \%$ & 11,87 & 15,41 \\
\hline & $60^{(\mathrm{e})}$ & 4 & $9 \%$ & 13,97 & 16,62 \\
\hline & $75^{(\mathrm{f})}$ & 9 & $20 \%$ & 13,15 & 16,99 \\
\hline \multicolumn{2}{|c|}{ (a) leituras de Pol realizadas de -10 DAA até 0 DAA } & \multicolumn{4}{|c|}{ (d) leituras de Pol realizadas de 31 DAA até 45 DAA. } \\
\hline \multicolumn{2}{|c|}{ (b) leituras de Pol realizadas de 1 DAA até 15 DAA. } & \multicolumn{4}{|c|}{ (e) leituras de Pol realizadas de 46 DAA até 60 DAA. } \\
\hline \multicolumn{2}{|c|}{ (c) leituras de Pol realizadas de 16 DAA até 30 DAA } & \multicolumn{4}{|c|}{ (f) leituras de Pol realizadas de 61 DAA até 75 DAA. } \\
\hline \multicolumn{6}{|c|}{ (g) $n=$ quantidade de leituras de Pol realizadas em cada momento. } \\
\hline \multicolumn{6}{|c|}{$\begin{array}{l}\text { (h) representatividade percentual da quantidade de leituras de Pol realizadas em cada momento }(\mathrm{n}) \text { sobre o somatório de } \\
\text { todas as leituras tabuladas }\left(\sum n \text { para Ethephon }=39 \text { leituras; } \sum n \text { para Etil-trinexapac }=7 \text { leituras; } \sum n \text { para Interdiário }=\right. \\
\text { Ethephon }+ \text { Etil-trinexapac }=46) \text {. }\end{array}$} \\
\hline
\end{tabular}

A partir dos valores percentuais de Pol descritos na Tabela 2, foram gerados números aleatórios entre aqueles valores mínimos e máximos e, com base nisso, foram simulados percentuais de Pol para 0 DAA, 15 DAA, 30 DAA, 45 DAA, 60 DAA e 75 DAA, para cada uma das 18 variedades descritas na Tabela 1, para cada um dos três maturadores considerados nos testes computacionais. A seguir, procedeu-se à aproximação polinomial com o auxílio de planilhas eletrônicas de cálculo e foram identificadas as respectivas funções de produtividade de Pol $P(x)$. Na sequência, com base nas funções $P(x)$, foram calculados os níveis percentuais máximos de Pol $\left(\right.$ Polmá $\left._{i}\right)$ que cada uma daquelas 18 variedades poderia atingir a partir da ação de cada um dos três maturadores considerados para a realização dos testes computacionais (Ethephon, Etil-trinexapac e o Intermediário), conforme mostra a Tabela 3.

Tabela 3 - Nível percentual máximo de sacarose estimado com base funções de produtividade de Pol $P(x)$ de cada maturador

\begin{tabular}{l|r|r|r|r}
\hline \multicolumn{2}{c|}{ Variedade } & $\begin{array}{r}\text { Polmáx } \\
\text { do Ethephon } \\
(\%)\end{array}$ & $\begin{array}{r}\text { Polmáx } \\
\text { d do Etil-trinexapac } \\
(\%)\end{array}$ & $\begin{array}{r}\text { Polmáx } \\
\text { Núme Intermediário } \\
(\%)\end{array}$ \\
\hline 1 & Identificação & 15,34 & 15,27 & 15,02 \\
2 & CTC15 & 15,16 & 15,09 & 15,08 \\
3 & CTC9 & 15,44 & 15,61 & 15,83 \\
4 & RB925211 & 14,75 & 15,49 & 15,18 \\
5 & CTC6 & 15,01 & 15,43 & 15,06 \\
6 & RB855156 & 14,33 & 15,10 & 13,89 \\
7 & CTC2 & 14,55 & 15,61 & 15,32 \\
8 & RB867515 & 15,70 & 15,83 & 14,80 \\
9 & SP80-1842 & 14,50 & 15,53 & 15,22 \\
10 & SP83-2847 & 15,65 & 15,12 & 15,13 \\
11 & SP80-3280 & 15,27 & 15,12 & 15,23 \\
12 & RB928062 & 15,15 & 15,93 & 15,49 \\
13 & RB966928 & 15,23 & 15,17 &
\end{tabular}


Tabela 3 - Nível percentual máximo de sacarose estimado com base funções de produtividade de Pol $P(x)$ de cada maturador

\begin{tabular}{|c|c|c|c|c|}
\hline \multicolumn{2}{|c|}{ Variedade } & \multirow{2}{*}{$\begin{array}{c}\text { Polmáx }_{i} \text { do Ethephon } \\
(\%)\end{array}$} & \multirow{2}{*}{$\begin{array}{c}\text { Polmáx }_{i} \text { do Etil-trinexapac } \\
(\%)\end{array}$} & \multirow{2}{*}{$\begin{array}{c}\text { Polmáx } x_{i} \text { do Intermediário } \\
(\%)\end{array}$} \\
\hline Número & Identificação & & & \\
\hline 14 & СТC17 & 15,51 & 15,27 & 15,24 \\
\hline 15 & SP81-3250 & 14,25 & 15,68 & 15,61 \\
\hline 16 & CTC4 & 15,37 & 15,08 & 14,94 \\
\hline 17 & RB92579 & 15,75 & 15,60 & 15,49 \\
\hline 18 & RB855453 & 15,24 & 15,31 & 14,20 \\
\hline
\end{tabular}

Fonte: elaborado pelo autor, com base nos dados da pesquisa.

Com relação à possibilidade de serem atribuídos pesos $(u$ e $v)$ aos desvios $\left(n_{1}\right.$ e $\left.p_{2}\right)$, inicialmente, o modelo proposto foi implementado sem pesos $(u=v=1)$ nas três instâncias. A seguir, ele foi implementado novamente com pesos $\mathrm{u}=0,90$ e $\mathrm{v}=0,10$, para $n_{1}$ e $p_{2}$ respectivamente, em todas as instâncias. E, finalmente, foram utilizados os pesos $u=0,10$ e $\mathrm{v}=0,90$, para $n_{1}$ e $p_{2}$ respectivamente, em todas as instâncias.

\section{Apresentação e Análise dos Resultados}

O modelo proposto nesta pesquisa foi testado em três cenários compostos por instâncias com dimensões distintas, conforme mostram os dados da Tabela 4. Valendo destacar que, no caso das instâncias $I-18$ e I-60, seus talhões foram ocupados pelas 18 variedades adaptáveis à região Centro-sul do Brasil escolhidas para a realização dos testes computacionais. Contudo, no caso da instância $I-30$, seus talhões foram ocupados por 15 variedades apenas, uma vez que as variedades CTC6, RB855453 e RB928062 não foram escolhidas para essa instância mediante o processo de sorteio por números aleatórios.

Tabela 4 - Resumo da composição de cada instância

\begin{tabular}{|c|c|c|c|c|c|c|}
\hline \multirow[t]{2}{*}{ Variedade } & \multicolumn{2}{|c|}{$I-18$} & \multicolumn{2}{|c|}{$I-30$} & \multicolumn{2}{|c|}{$I-60$} \\
\hline & $\begin{array}{l}\text { Quantidade } \\
\text { de talhões } \\
\text { (un.) }\end{array}$ & $\begin{array}{c}\text { Área } \\
\text { ocupada } \\
\text { (ha) }\end{array}$ & $\begin{array}{c}\text { Quantidade } \\
\text { de talhões } \\
\text { (un.) }\end{array}$ & $\begin{array}{c}\text { Área } \\
\text { ocupada } \\
\text { (ha) }\end{array}$ & $\begin{array}{c}\text { Quantidade } \\
\text { de talhões } \\
\text { (un.) }\end{array}$ & $\begin{array}{c}\text { Área } \\
\text { ocupada } \\
\text { (ha) }\end{array}$ \\
\hline CTC15 & 1 & 19 & 1 & 21 & 3 & 99 \\
\hline СТC17 & 1 & 40 & 2 & 48 & 5 & 132 \\
\hline CTC2 & 1 & 44 & 3 & 120 & 2 & 66 \\
\hline СТC20 & 1 & 48 & 3 & 100 & 4 & 120 \\
\hline CTC4 & 1 & 20 & 1 & 21 & 5 & 186 \\
\hline CTC6 & 1 & 19 & 0 & 0 & 1 & 48 \\
\hline CTC9 & 1 & 42 & 2 & 40 & 6 & 189 \\
\hline RB855156 & 1 & 29 & 2 & 59 & 3 & 119 \\
\hline RB855453 & 1 & 39 & 0 & 0 & 3 & 96 \\
\hline RB867515 & 1 & 43 & 3 & 121 & 2 & 88 \\
\hline RB925211 & 1 & 27 & 1 & 20 & 1 & 19 \\
\hline RB92579 & 1 & 42 & 1 & 34 & 4 & 158 \\
\hline RB928062 & 1 & 42 & 0 & 0 & 6 & 174 \\
\hline
\end{tabular}


Tabela 4 - Resumo da composição de cada instância

\begin{tabular}{|c|c|c|c|c|c|c|}
\hline \multirow[t]{2}{*}{ Variedade } & \multicolumn{2}{|c|}{$I-18$} & \multicolumn{2}{|c|}{$I-30$} & \multicolumn{2}{|c|}{$I-60$} \\
\hline & $\begin{array}{c}\text { Quantidade } \\
\text { de talhões } \\
\text { (un.) }\end{array}$ & $\begin{array}{c}\text { Área } \\
\text { ocupada } \\
\text { (ha) }\end{array}$ & $\begin{array}{l}\text { Quantidade } \\
\text { de talhões } \\
\text { (un.) }\end{array}$ & $\begin{array}{c}\text { Área } \\
\text { ocupada } \\
\text { (ha) }\end{array}$ & $\begin{array}{l}\text { Quantidade } \\
\text { de talhões } \\
\text { (un.) }\end{array}$ & $\begin{array}{c}\text { Área } \\
\text { ocupada } \\
\text { (ha) }\end{array}$ \\
\hline RB966928 & 1 & 48 & 2 & 71 & 2 & 51 \\
\hline SP80-1842 & 1 & 36 & 4 & 169 & 3 & 100 \\
\hline SP80-3280 & 1 & 34 & 2 & 53 & 1 & 23 \\
\hline SP81-3250 & 1 & 45 & 2 & 70 & 4 & 130 \\
\hline SP83-2847 & 1 & 25 & 1 & 18 & 5 & 176 \\
\hline Total & 18 & 642 & 30 & 965 & 60 & 1974 \\
\hline
\end{tabular}

Fonte: elaborado pelo autor, com base nos dados da pesquisa.

Ao levar em conta as áreas de cada talhão $j$, as respectivas variedades e suas capacidades produtivas ( $\mathrm{TCH}$ e Pol), foram estabelecidas as metas de sacarose demandada para a safra $(D)$, bem como, o orçamento de gastos para a compra de agentes indutores de maturação $(C)$ a serem utilizados em toda a safra, conforme descrito na Tabela 5. Em relação à demanda de sacarose $(D)$, a definição do valor meta em toneladas ( $\mathrm{t}$ ) levou em conta as áreas dos talhões $j$ e a capacidade produtiva ( $\mathrm{TCH}$ ha $^{-1}$ e Pol t ${ }^{-1}$ ) de cada variedade. Em relação ao orçamento de gastos para a compra de maturadores $(C)$, a definição do valor meta em reais $(\mathrm{R} \$)$ levou em conta a área de cada talhão, a média das doses a serem aplicadas de cada maturador $i\left(0,66 \mathrm{~L} \mathrm{ha}^{-1}\right.$ para o Ethephon, 1,00 L ha ${ }^{-1}$ para o Etil-trinexapac e 1,00 L ha ${ }^{-1}$ para o Intermediário) e, ainda, a média dos respetivos preços de mercado $\left(\mathrm{R} \$ 180,0 \mathrm{~L}^{-1}\right.$ para o Ethephon, $\mathrm{R} \$ 110,0 \mathrm{~L}^{-1}$ para o Etiltrinexapac e $\mathrm{R} \$ 114,40 \mathrm{~L}^{-1}$ para o Intermediário).

Tabela 5 - Resultados da aplicação do modelo para cada cenário/instância

\begin{tabular}{|c|c|c|c|c|c|c|c|c|}
\hline \multirow[t]{2}{*}{ Instância } & \multirow[t]{2}{*}{ Parâmetros } & \multirow[t]{2}{*}{ Meta } & \multicolumn{2}{|c|}{$\begin{array}{l}\text { Resultados do modelo: } \\
\quad u=1,00 \text { e } v=1,00\end{array}$} & \multicolumn{2}{|c|}{$\begin{array}{c}\text { Resultados do modelo: } \\
u=0,90 \text { e } v=0,10\end{array}$} & \multicolumn{2}{|c|}{$\begin{array}{l}\text { Resultados do modelo: } \\
u=0,10 \text { e } v=0,90\end{array}$} \\
\hline & & & Total & Desvio & Total & Desvio & Total & Desvio \\
\hline \multirow[t]{2}{*}{$I-18$} & $D(\mathrm{t})$ & 11.903 & 12.420 & 517 & 12.420 & 517 & 12.361 & 458 \\
\hline & $C(\mathrm{R} \$)$ & $73.445,00$ & $73.370,00$ & $-75,00$ & $73.370,00$ & $-75,00$ & $73.440,40$ & $-4,60$ \\
\hline \multirow[t]{2}{*}{$I-30$} & $D(\mathrm{t})$ & 18.088 & 18.964 & 876 & 19.022 & 934 & 18.958 & 870 \\
\hline & $C(\mathrm{R} \$)$ & $110.396,00$ & $110.312,40$ & $-83,60$ & $110.369,60$ & $-26,40$ & $110.396,00$ & 0,00 \\
\hline \multirow[t]{2}{*}{$I-60$} & $D(\mathrm{t})$ & 36.530 & 36.530 & 0 & 36.530 & 0 & 36.530 & 0 \\
\hline & $C(\mathrm{R} \$)$ & $225.825,00$ & $218.213,60$ & $-7.611,40$ & $218.213,60$ & $-7.611,40$ & $218.213,60$ & $-7.611,40$ \\
\hline
\end{tabular}

Fonte: elaborado pelo autor, a partir dos dados pesquisa.

Ao minimizar os desvios negativos $\left(n_{1}\right)$ em relação a $D$ e os desvios positivos $\left(p_{2}\right)$ em relação a $C$, sem considerar nenhuma ponderação, portanto com pesos iguais a um $(u=1,00 \mathrm{e}$ $v=1,00$ ), o modelo matemático de otimização para a seleção de maturadores fez com que a produção de sacarose prevista fosse superior às respectivas demandas $(D)$ nas instâncias $I$-18 e $I$ 30, sendo que, na instância I-60, o modelo garantiu o cumprimento da respectiva meta, conforme mostram as informações resumidas na Tabela 5. Adicionalmente, pode-se observar que, nas três 
instâncias o valor calculado pelo modelo para o gasto com a aquisição de maturadores foi inferior ao respectivo orçamento $(C)$.

Ainda com base nas informações resumidas na Tabela 5, pode-se observar que mesmo com a atribuição de pesos $(u=0,10$ e $v=0,90 ; u=0,10$ e $v=0,90)$ para os desvios $\left(n_{1}\right.$ e $p_{2}$, respectivamente), o modelo matemático de otimização para a seleção de maturadores se comportou de forma satisfatória.

No caso dos pesos/prioridades $u=0,90$ e $v=0,10$ para $n_{1}$ e $p_{2}$ respectivamente, o valor identificado pelo modelo para realização de gastos com a aquisição de maturadores foi inferior ao respectivo orçamento $(C)$, e a produção prevista de sacarose foi, no mínimo, igual à respectiva demanda $(D)$ no caso de I-60. Sendo que, em I-18 e I-30, a produção de sacarose calculada pelo modelo foi superior às respectivas demandas $(D)$.

No caso dos pesos/prioridades $u=0,10$ e $v=0,90$ para $n_{1}$ e $p_{2}$ respectivamente, o valor identificado pelo modelo para realização de gastos com a aquisição de maturadores foi inferior ao respectivo orçamento $(C)$ nas instâncias $I-18$ e $I-60$ e, ainda, igual ao orçamento na instância $I$-30. Sendo que, em relação à produção de sacarose o modelo foi capaz de, no mínimo, garantir que a respectiva demanda $(D)$ fosse atendida.

Uma informação importante, que também pôde ser extraída a partir dos dados resumidos na Tabela 5, diz respeito à compreensão acerca de como o modelo se comportou em instâncias menores. Isto é, apesar de atingir o objetivo para o qual o modelo foi proposto, ou seja, garantir que a produção de sacarose atenda à respectiva de demanda $(D)$ e, simultaneamente, garantir que o orçamento para a aquisição de maturadores $(C)$ seja cumprido, tudo isso levando em conta o efeito que esse tipo de agente fisiológico tem sobre o ganho de produtividade sacarose (Polmáx $x_{i}$, pôde-se perceber que em instâncias menores (com menos talhões, como é caso de I-18 ou com uma quantidade menor de variedades, como é o caso de I-30), a economia orçamentária foi menor, contudo, o ganho de produtividade de sacarose é mais evidente.

Por outro lado, em instâncias maiores (como é o caso de I-60) ficou evidente que a produtividade de sacarose é uma variável mais sensível que as possíveis economias orçamentárias, pois, o modelo conseguiu garantir o atendimento da demanda por sacarose $(D)$, mas, não conseguiu superá-la como aconteceu nas instâncias menores (I-18 e I-30). Já em relação ao orçamento para aquisição de maturadores $(C)$, nem mesmo a atribuição de pesos e sua inversão (de $u=0,90$ e $v=0,10$ para $u=0,10$ e $v=0,90$ ) fizeram com que o valor previsto pelo modelo fosse alterado.

Com relação ao poder informativo do modelo matemático de otimização para a seleção de maturadores, deve-se destacar que ele foi além das informações totalizadas e de caráter 
consolidado, como foi o caso das informações resumidas na Tabela 5. Ou seja, devido ao fato do modelo matemático de otimização proposto levar em conta o efeito de cada agente maturador sobre o ganho (incremento ou melhora) de produtividade sacarose das variedades cultivadas $\left(\right.$ Polmáx $\left._{i}\right)$, foi possível identificar também qual maturador $i$ é mais adequado à variedade plantada em cada talhão $j$, de forma que se possa saber previamente quanto comprar de cada agente indutor de maturação $i$ e, ainda, onde ele deve ser aplicado.

Apesar de ser possível produzir esse conjunto de informações para problemas de qualquer tamanho (de instâncias menores até instâncias maiores), o exemplo descrito na Tabela 6 refere-se à instância $I-18$ e ilustra bem a capacidade informativa que pode ser obtida a partir dos resultados da aplicação modelo proposto por esta investigação científica.

Tabela 6 - Detalhamento dos gastos com maturadores identificados pelo modelo para a instância $I$ - 18

\begin{tabular}{|c|c|c|c|c|c|c|c|c|c|c|c|c|c|c|}
\hline \multirow[t]{3}{*}{$j$} & \multirow[t]{3}{*}{ Variedade } & \multirow[t]{3}{*}{$H_{j}$} & \multicolumn{4}{|c|}{$\begin{array}{c}\text { Previsto, sendo: } \\
u=1,00 \text { e } v=1,00\end{array}$} & \multicolumn{4}{|c|}{$\begin{array}{c}\text { Previsto, sendo: } \\
u=0,90 \text { e } v=0,10\end{array}$} & \multicolumn{4}{|c|}{$\begin{array}{c}\text { Previsto, sendo: } \\
u=0,10 \text { e } v=0,90\end{array}$} \\
\hline & & & \multicolumn{4}{|c|}{ Maturador } & \multicolumn{4}{|c|}{ Maturador } & \multicolumn{4}{|c|}{ Maturador } \\
\hline & & & $i^{\text {(a) }}$ & $\begin{array}{c}c c_{j} \\
\left(\mathrm{R} \$ \mathrm{~L}^{-1}\right)\end{array}$ & \begin{tabular}{|c|} 
Qtd. $^{(\mathrm{b})}$ \\
(L)
\end{tabular} & $\begin{array}{c}C_{j} \\
(\mathrm{R} \$) \\
\end{array}$ & $i^{(\mathrm{a})}$ & $\begin{array}{c}c c_{j} \\
\left(\mathrm{R} \$ \mathrm{~L}^{-1}\right)\end{array}$ & \begin{tabular}{|c|} 
Qtd. $^{(\mathrm{b})}$ \\
(L)
\end{tabular} & $\begin{array}{c}C_{j} \\
(\mathrm{R} \$) \\
\end{array}$ & $i^{(a)}$ & $\begin{array}{c}c c_{j} \\
\left(\mathrm{R} \$ \mathrm{~L}^{-1}\right)\end{array}$ & \begin{tabular}{|c|} 
Qtd. $^{\left({ }^{b}\right)}$ \\
(L)
\end{tabular} & $\begin{array}{c}C_{j} \\
(\mathrm{R} \$) \\
\end{array}$ \\
\hline 1 & CTC15 & 19 & 2 & 110,00 & 19,00 & $2.090,00$ & 2 & 110,00 & 19,00 & $2.090,00$ & 3 & 114,40 & 19,00 & $2.173,60$ \\
\hline 14 & CTC17 & 40 & 3 & 114,40 & 40,00 & $4.576,00$ & 3 & 114,40 & 40,00 & $4.576,00$ & 3 & 114,40 & 40,00 & $4.576,00$ \\
\hline 6 & СТC2 & 44 & 3 & 114,40 & 44,00 & $5.033,60$ & 3 & 114,40 & 44,00 & $5.033,60$ & 3 & 114,40 & 44,00 & $5.033,60$ \\
\hline 13 & СТC20 & 48 & 2 & 110,00 & 48,00 & $5.280,00$ & 2 & 110,00 & 48,00 & $5.280,00$ & 2 & 110,00 & 48,00 & $5.280,00$ \\
\hline 16 & CTC4 & 20 & 1 & 180,00 & 13,20 & $2.376,00$ & 1 & 180,00 & 13,20 & $2.376,00$ & 1 & 180,00 & 13,20 & $2.376,00$ \\
\hline 4 & СTC6 & 19 & 2 & 110,00 & 19,00 & $2.090,00$ & 2 & 110,00 & 19,00 & $2.090,00$ & 3 & 114,40 & 19,00 & $2.173,60$ \\
\hline 2 & СТC9 & 42 & 2 & 110,00 & 42,00 & $4.620,00$ & 2 & 110,00 & 42,00 & $4.620,00$ & 3 & 114,40 & 42,00 & $4.804,80$ \\
\hline 5 & RB855156 & 29 & 3 & 114,40 & 29,00 & $3.317,60$ & 3 & 114,40 & 29,00 & $3.317,60$ & 3 & 114,40 & 29,00 & $3.317,60$ \\
\hline 18 & RB855453 & 39 & 1 & 180,00 & 25,74 & $4.633,20$ & 1 & 180,00 & 25,74 & $4.633,20$ & 3 & 114,40 & 39,00 & $4.461,60$ \\
\hline 7 & RB867515 & 43 & 3 & 114,40 & 43,00 & $4.919,20$ & 3 & 114,40 & 43,00 & $4.919,20$ & 3 & 114,40 & 43,00 & $4.919,20$ \\
\hline 3 & RB925211 & 27 & 1 & 180,00 & 17,82 & $3.207,60$ & 1 & 180,00 & 17,82 & $3.207,60$ & 1 & 180,00 & 17,82 & $3.207,60$ \\
\hline 17 & RB92579 & 42 & 3 & 114,40 & 42,00 & $4.804,80$ & 3 & 114,40 & 42,00 & $4.804,80$ & 3 & 114,40 & 42,00 & $4.804,80$ \\
\hline 11 & RB92 & 42 & 3 & 114,40 & 42,00 & $4.804,80$ & 3 & 114,40 & 42,00 & $4.804,80$ & 3 & 114,40 & 42,00 & $4.804,80$ \\
\hline 12 & RB966928 & 48 & 3 & 114,40 & 48,00 & $5.491,20$ & 3 & 114,40 & 48,00 & $5.491,20$ & 3 & 114,40 & 48,00 & $5.491,20$ \\
\hline 8 & SP80-1842 & 36 & 3 & 114,40 & 36,00 & $4.118,40$ & 3 & 114,40 & 36,00 & $4.118,40$ & 3 & 114,40 & 36,00 & $4.118,40$ \\
\hline 10 & SP80-3280 & 34 & 3 & 114,40 & 34,00 & $3.889,60$ & 3 & 114,40 & 34,00 & $3.889,60$ & 3 & 114,40 & 34,00 & $3.889,60$ \\
\hline 15 & SP81-3250 & 45 & 3 & 114,40 & 45,00 & $5.148,00$ & 3 & 114,40 & 45,00 & $5.148,00$ & 3 & 114,40 & 45,00 & $5.148,00$ \\
\hline 9 & SP83-2847 & 25 & 1 & 180,00 & 16,50 & $2.970,00$ & 1 & 180,00 & 16,50 & $2.970,00$ & 3 & 114,40 & 25,00 & $2.860,00$ \\
\hline \multicolumn{3}{|c|}{ Total } & \multicolumn{4}{|c|}{$73.370,00$} & & \multirow{2}{*}{\multicolumn{3}{|c|}{$73.370,00$}} & \multicolumn{4}{|r|}{$73.440,40$} \\
\hline \multicolumn{12}{|c|}{ exapac; $3=$ Intermediário } & & & \\
\hline & & & & & & & & & & & & & & \\
\hline
\end{tabular}

Fonte: elaborado pelo autor, a partir dos dados pesquisa.

Conforme pode ser visto na Tabela 6 , de acordo com cada uma das três situações simuladas para instância I-18 para variações de pesos nos desvios minimizados, modelo matemático de otimização para a seleção de maturadores procedeu alterações acerca da utilização de um determinado agente maturador $i$ em relação aos talhões $j$ em que se encontra determinada variedade de cana-de-açúcar.

Assim, para a situação em que não foram atribuídos pesos para os desvios, portanto, $u=$ 1,00 e $v=1,00$, e para a situação em que foi atribuído maior peso para o desvio em relação à 
produção de sacarose $\left(n_{1}\right)$, ou seja, $u=0,90$ e $v=0,10$ para $n_{1}$ e $p_{2}$ respectivamente, o modelo proposto estimou um total de 604,26 litros (L) de maturadores a serem adquiridos, sendo: 73,26 L de Ethephon; 128,00 L de Etil-trinexapac; e, 403,00 L do maturador Intermediário.

Por outro lado, para a situação em que foi atribuído maior peso para o desvio em relação ao orçamento de compras de maturadores $\left(p_{1}\right)$, portanto, $u=0,10$ e $v=0,90$ para $n_{1}$ e $p_{2}$ respectivamente, o modelo proposto estimou um total de 626,02 L de maturadores a serem adquiridos, sendo: 31,02 L de Ethephon; 48,00 L de Etil-trinexapac; e, 547,00 L do maturador Intermediário.

\section{CONSIDERAÇÕES FINAIS}

O modelo de otimização proposto nesta pesquisa científica permite planejar os processos de escolha, compra e aplicação de agentes indutores de maturação da cana-de-açúcar, de forma que a demanda por sacarose da safra seja atendida e, ainda, faz com que o orçamento destinado à aquisição dessas substâncias (maturadores) seja cumprido com possíveis economias.

Adicionalmente, a formulação utilizada para composição do modelo proposto permite produzir um conjunto de informações que vai além das variáveis relacionadas à produção e demanda de sacarose e em relação aos valores orçamentários. Ou seja, é possível identificar previamente quanto comprar de cada tipo de maturador, quanto será gasto por tipo de maturador, e, ainda, em qual talhão cada maturador deve ser aplicado para que se atinja a máxima produtividade de sacarose mediante a interação entre o respectivo agente indutor de maturação e determinada variedade de cana-de-açúcar.

Como principal limitação desta pesquisa, destaca-se a necessidade de se conhecer a função estimadora da produtividade máxima de sacarose alcançada mediante o uso de determinado agente indutor de maturação $\left(\right.$ Polmáx $\left._{i}\right)$. Entretanto, tal dificuldade pode ser superada mediante a realização de experimentos de campo para que se consiga melhor acuracidade nas estimativas relacionadas à ação de certo agente fisiológico sobre certa cultivar de cana-de-açúcar. Por outro lado, também deve ser destacado que são crescentes os estudos relacionados a essa temática, o que pode facilitar também a estimativa da função em questão.

Para a continuidade dos estudos acerca do tema, sugere-se a elaboração de estudos envolvendo outras variáveis relacionadas à qualidade e produtividade da cultura da cana-deaçúcar, por exemplo, brix, teor de fibras, produtividade de palhiço, potencial calorífico, entre outras.

Dessa forma, espera-se que os resultados alcançados a partir da proposição e aplicação da modelagem desta investigação científica possam ser somados aos resultados de outras pesquisas 
de natureza correlata e, assim, se possa contribuir para o processo de produção de informações destinadas ao suporte à tomada de decisões gerenciais no setor sucroenergético.

\section{REFERÊNCIAS}

CAPUTO, M. M.; SILVA, M. A. de; BEAUCLAIR, E. G. F. de; GAVA, G. J. C. de. Acúmulo de sacarose, produtividade e florescimento de cana-de-açúcar sob reguladores vegetais.

Interciência, [S. 1.], v. 32, n. 12, p. 834-840, Dez. 2007. Disponível em: https://repositorio.unesp.br/bitstream/handle/11449/70199/WOS000251975400006.pdf?sequence =1\&isAllowed=y. Acesso em: 06 fev. 2020.

COLAPINTO, C.; JAYARAMAN, R.; MARSIGLIO, S.. Multi-criteria decision analysis with goal programming in engineering, management and social sciences: a state-of-the art review. Ann. Oper. Res. (Springer Science \& Business Media, LLC), [S. 1.], v. 251, p. 7-40, 2017. Disponível em: https://link.springer.com/content/pdf/10.1007\%2Fs10479-015-1829-1.pdf. Acesso em: 27 mar. 2019.

CRUSCIOL, C. A. C.; LEITE, G. H. P.; SIQUEIRA, G. F. de; SILVA, M. de A.. Response of application of growth inhibitors on sugarcane productivity and sucrose accumulation in the middle of cropping season in Brazil. Sugar Tech, Cham (Switzerland), v 19, n. 2, p. 155-164, April, 2017. Disponível em: https://doi.org/10.1007/s12355-016-0450-1. Acesso em: 27 ago. 2018.

DIDIER, K. K.; CRÉPIN, P. B.; CARINE, N. A.; MÉLANIE, B. B.; YAH, O.; MICHEL, Z.. Effect of glyphosate used as a sugarcane chemical ripener in Côte d'Ivoire. African Journal Plant Science, Victoria Island, Lagos (Nigeria), v.11, n 8. p. 341-350, August 2017. Disponível em: https://academicjournals.org/journal/AJPS/article-full-text/B37BE1665315. Acesso em: 23 out. 2018.

INOUE, M. H.; CAPPELLESSO, E. J. de S.; MENDES, K. F.; BEN, R.; CONCIANI, P. A.. Eficiência do bispyribac-sodium como maturador na cultura da cana-de-açúcar. Revista Ciência Agronômica, Fortaleza, v. 46, n. 1, p. 80-88, jan.-mar., 2015. Disponível em: http://ccarevista.ufc.br/seer/index.php/ccarevista/article/view/2276/1066. Acesso em: 06 fev. 2020.

JONES, D.; TAMIZ, M.. Practical goal programming. New York: Springer Science \& Business Media, 2010.

LEITE, G. H. P.; CRUSCIOL, C. A. C.; SILVA, M. de A.. Desenvolvimento e produtividade da cana-de- açúcar após aplicação de reguladores vegetais em meio de safra. Semina: Ciências Agrárias, Londrina, v. 32, n. 1, p. 129-138, jan./mar. 2011. Disponível em: http://www.uel.br/revistas/uel/index.php/semagrarias/article/view/4334/7123. Acesso em: 20 ago. 2018.

LOPES, C. H. (Org.). Tecnologia de produção de açúcar de cana. São Carlos: Ed. UFSCar, 2011. Disponível em: http://livresaber.sead.ufscar.br:8080/jspui/handle/123456789/2769.

Acesso em: 14 ago. 2018.

LORIZOLA, G. M.; CAPITANI, D. H. D.. Análise do modelo estrutura-conduta-desempenho do setor sucroenergértico brasileiro. Nucleus, Ituverava, v.15, n.2, p.383-399, out. 2018. Disponível em: http://dx.doi.org/10.3738/1982.2278.2920. Acesso em: 01 set. 2019.

Nucleus, v.17, n.2, out.2020 
MARIN, F. R.; PELLEGRINO, G. Q.; ASSAD, E. D.; PINTO, H. S. P.; ZULLO JUNIOR, J.. Cana-de-açúcar. In: MONTEIRO, José Eduardo B. A. (org.). Agrometeorologia dos cultivos: o fator meteorológico na produção agrícola. - Brasília, DF: INMET, 2009. p. 109-130. Disponível em:

http://www.inmet.gov.br/portal/css/content/home/publicacoes/agrometeorologia_dos_cultivos.pd f. Acesso em: 13 ago. 2018.

MUHWIRIDZWA, M.; MANENJI, B. T.; MADANZI, T.; MAHOHOMA, W.. Evaluating the effects of chemical ripening with fluazifop-p-butyl on sugarcane (Saccharum officinarum) yield and sugar content. International Journal of Plant \& Soil Science, West Bengal (India), v. 9, n. 6, p. 1-8, 2016. Disponível em:

http://www.journalrepository.org/media/journals/IJPSS_24/2016/Jan/Manenji962015IJPSS20596 .pdf. Acesso em: 23 out. 2018.

NERVIS, J. J.; FLORENTINO, H. de O.; CANTANE, D. R.; RAMOS, R. P.; ISLER, P. R.. Simulação para a otimização da colheita da cana-de-açúcar. Revista Brasileira de Biometria, [S. 1.], v. 35, n. 2, p. 415-439, jun. 2017. Disponível em: http://www.biometria.ufla.br/index.php/BBJ/article/view/47. Acesso em: 24 out. 2018.

OLIVEIRA FILHO, P. B. de; DUARTE JÚNIOR, J. B.; COSTA, A. C. T. da; OLIVEIRA, P. S. R. de; MACEDO JÚNIOR, E. K.; GUIMARÃES, V. F.; BOSQUETTE, W.. Chemical ripeners and different harvest periods in sugarcane in State of Paraná, southern Brazil. African Journal of Agricultural Research, [S. 1.], n. 11, n. 39, p. 3904-3913, sept., 2016. Disponível em: https://academicjournals.org/journal/AJAR/article-full-text-pdf/DFD026F60880. Acesso em: 06 fev. 2020.

ORGERON, A. J; GRAVOIS, K. A.; LEGENDRE, B. L.; GRIFFIN, J. L.. On-farm evaluation of trinexapac-ethyl for early season sucrose enhancement. Journal of American Society of Sugar Cane Technologists, Baton Rouge, LA (EUA), v. 36, p. 1-8, 2016. Disponível em: http://www.assct.org/journal/JASSCT\%20PDF\%20Files/Volume\%2036/OnFarm\%20Evaluation\%20of\%20Trinexapacethyl\%20for\%20Early\%20Season\%20Sucrose\%20Enhancem....pdf. Acesso em: 20 out. 2018.

RAIZER, A. J.; BRAGA JÚNIOR, R. L. do C.; SELEGATO, S. M.. Índices de eficiência no uso de variedades de cana-de-açúcar. RPA News - cana \& indústria, Ribeirão Preto, ano 12, n. 151/152, p. 25-29, jul./ago. 2013. Disponível em: http://revistarpanews.com.br/edicoes/151/IDEANews151e152FinalGraficaWeb.pdf. Acesso em: 26 abr. 2019.

RAMOS, R. P.; ISLER, P. R.; FLORENTINO, H. de O.; JONES, D.; NERVIS, J. J.. An optimization model for the combined planning and harvesting of sugarcane with maturity considerations. African Journal of Agricultural Research (Afr. J. Agric. Res.), [S. 1.], v. 11, n. 40, p. 3950-3958, 6 Oct., 2016. Disponível em: https://academicjournals.org/journal/AJAR/article-full-text-pdf/84FBC7A60937. Acesso em: 13 abr. 2019. 
ROBERTO, G. G. ; CUNHA, C.; SALES, C. R. G.; . SILVEIRA, N. M.; RIBEIRO, R. V.; MACHADO, E. C.; LAGÔA, A. M. M. A.. Variação da fotossíntese e dos teores de carboidratos induzidos por etefom e déficit hídrico na fase de maturação da cana-de-açúcar. Bragantia, Campinas, v.74, n. 4, p.379-386, out./dez. 2015. Disponível em: http://dx.doi.org/10.1590/16784499.0062. Acesso em: 18 set. 2018.

SIDRA, Sistema IBGE de Recuperação Automática. Censo agropecuário: tabela 6615 - número de estabelecimentos agropecuários, quantidade produzida e area colhida, por produtos da lavoura temporária, resultados preliminares 2017. [S. 1.]: 2019. Disponível em:

https://biblioteca.ibge.gov.br/visualizacao/livros/liv61914.pdf. Acesso em: 26 abr. 2019. Acesso em: 26 abr. 2019.

VIANA, R. da S.; SILVA, P. H.; MUTTON, M. A.; MUTTON, M. J. R.; GUIMARÂES, E. R.; BENTO, M.. Efeito da aplicação de maturadores químicos na cultura da cana de cana-de-açúcar (Saccharum spp.) variedade SP81-3250 . Acta Sci. Agron., Maringá, v. 30, n. 1, p. 65-71, 2008. Disponível em: http://dx.doi.org/10.4025/actasciagron.v30i1.1130. Acesso em: 06 fev. 2020..

VIANA, R. da S.; FIGUEIREDO, P. A. M.; LISBOA, L. A. M.; PASCOALOTO, I. M. Características morfoanatômicas de folhas de cana-de-açúcar sob efeito residual de maturadores. Revista Brasileira de Herbicidas, Londrina, v.14, n.4, p.306-314, out./dez. 2015. Disponível em: https://doi.org/10.7824/rbh.v14i4.438. Acesso em: 27 out. 2018.

VIANA, R. da S.; LISBOA, L. A. M.; FIGUEIREDO, P. A. M.; RODRIGUES NETO, A. D.. Parâmetros tecnológicos e produtivos da cana-de-açúcar quando submetida à aplicação de maturadores químicos no início de safra. Revista Brasileira de Herbicidas, Londrina v. 16, n.1, p.67-75, jan./mar. 2017(a). Disponível em: https://doi.org/10.7824/rbh.v16i1.496. sso em: 06 fev. 2020. 